政

\title{
A educação no diário de uma imigrante britânica e em outros escritos na província do Paraná
}

\author{
Ana Maria Rufino Gillies \\ Universidade Estadual do Centro-Oeste
}

\section{Resumo}

Este artigo discute a experiência de uma imigrante britânica que viveu na Província do Paraná entre os anos de 1868 e 1888, onde atuou como professora a partir de 1874 . Para acompanhar sua trajetória, foram consultados relatórios administrativos e correspondências escritos por membros dos governos imperial e provincial, relativamente à colônia do Assungui, para onde ela, o marido, os filhos e outros imigrantes foram enviados em 1868; periódicos da província; memórias escritas por seu neto Albert; cartas escritas por ela e pelo marido e um diário mantido por ela entre os anos de 1880 e 1882. Desse conjunto documental, problematizamos a educação em face de uma escrita autobiográfica, assim como as condições enfrentadas para ensinar na colônia: a falta de livros e de locais adequados, a dificuldade para receber do governo as suas 'gratificações'; os requisitos para ensinar na capital, a inconstância do alunato particular, o debate acercado que ensinar para as mulheres no Brasil e na Inglaterra; as seleções de leituras para educar-se e a educação dos filhos.

51 Palavras-chave: Escrita autobiográfica. Educação e gênero. Brasil e Inglaterra no século XIX.

\section{Educationin the diary of a British immigrant and in other writings at the province of Paraná}

\section{Abstract}

This text discusses the experience of a British immigrant who lived in the Province of Paraná, South of Brazil, between the years of 1868 and 1888 and who worked as a teacher as of 1874. To follow her steps the following documents were consulted: the correspondence and reports written by members of the provincial and imperial government about the colony of Assungui, to where she, her husband, her children and other immigrants were sent to in 1868; periodicals of the province; a memoir written by her grandson Albert; letters written by her and her husband and a diary that she kept during 1880 and 1882. Based on these documents we discuss education in face of an autobiographic writing and the conditions faced to teach at the colony: the lack of books and appropriate classrooms, the difficulty to get paid; the requirements to teach at the capital, the inconstancy of private students, the debate on what to teach women in Brazil and in England; the selection of books to educate herself and the education of her children.

Keywords: Autobiographical writings. Education and gender. Brazil and England in the nineteenth-century. 
A educação no diário de uma imigrante britânica e em outros escritos na província do Paraná

\section{Educación en el diario de una inmigrante británica y en otros escritos en la provincia de Paraná}

\section{Resumen}

Este artículo describe la experiencia de una inmigrante británico que vivió en la provincia de Paraná entre los años 1868 y 1888, donde se desempeñó como profesor desde 1874. Para seguir su trayectoria se consultó a los informes administrativos escritos por miembros de los gobiernos imperiales y provinciales, correspondencia y informes escritos por los miembros de los gobiernos imperial y provincial en relación con la colonia Assungui, donde ella, su esposo, hijos y otros inmigrantes fueron enviados en 1868; revistas provinciales; memorias escritas por su nieto Albert; cartas escritas por ella y su marido y un diario escrito por ella entre los años 1880 y 1882 . Con este conjunto de documentos fue posible discutir la educación y las dificultades que tienen para enseñar en la colonia: la falta de libros y lugares adecuados, la dificultad para recibir del gobierno sus 'gratificacións'; los requisitos para enseñar en la capital, la inconstancia de alunado particular, el debate sobre qué enseñar a las mujeres en Brazil y en Inglaterra; las selecciones de lecturas para educar a sí mismo y a sus hijos.

Palabras clave: Escritura autobiográfica. Educación y Género. Brasil y Inglaterra en

52 siglo XIX.

\section{A educação como símbolo de distinção}

Em maio de 1871, a imigrante britânica D. Caroline Tamplin escreveu para sua cunhada na Inglaterra, Mrs. Elizabeth Little, uma longa carta. Naquela data, Caroline morava em Turvo, um dos núcleos da colônia do Assungui, a cem quilômetros de Curitiba, capital da província do Paraná. As cartas demoravam para chegar aos seus destinatários e também, certamente, para chegar até a colônia, considerando as inúmeras queixas que os colonos registravam e os pedidos para que fosse instalado um correio permanente no lugar. Caroline valorizava muito essas correspondências, e registrava, cuidadosamente, em seu diário, as enviadas e as recebidas. Aguardadas com ansiedade, elas detalhavam todos os grandes e pequenos acontecimentos do dia a dia daqueles que estavam longe uns dos outros. Naturalmente, para manter correspondência com outras pessoas, era preciso estar alfabetizada, saber escrever, e Caroline escrevia bem. Relatos privados do cotidiano, a leitura dessa missiva permite conhecer, além dos modos de viver, a maneira de pensar, os valores, 
as ansiedades, incertezas, esperanças. Graças ao desenvolvimento das discussões iniciadas por Lucien Fébvre e Marc Bloch, nas primeiras décadas do século XX, e mesmo antes, se considerarmos uma seleção de outros autores, a história cultural e a história da educação podem construir narrativas do passado a partir desses registros produzidos no âmbito da vida privada, como as cartas, os diários íntimos, as memórias e inúmeros outros papéis. Afinal, passamos nossas vidas produzindo papéis, e se, de vez em quando, fazemos uma triagem, jogando alguns fora, iá que não guardamos todas as maçãs do nosso cesto pessoal, como diz Philippe Artières (1998), outros tantos são selecionados e mantidos. Dessa forma, vamos arquivando nossas vidas, e, graças a essa prática, ficam preservados fragmentos, vestígios do passado com os quais pode trabalhar o historiador.

Na carta de maio de 1871, D. Caroline compartilhou com a família na Inglaterra um conjunto de informações acerca das condições de vida na distante colônia do Assungui, seu pensamento referente aos brasileiros, sua revolta em relação à conduta do diretor da colônia, o desconforto da 'selvagem vida no mato, tão diferente de todos os confortos e elegâncias da vida em Londres' I wild wood lives out here, so different from all the comforts \& elegancies of London life). Elegante mesmo pode ter sido. Na certidão de casamento que um familiar dela nos enviou recentemente, consta o nome de seu pai, Edward Maxwell, cuja profissão informa: gentleman. Não se tratava, à época, de identificar apenas um homem portador de personalidade que reunia o ideal inglês de educação, modos refinados, altruísmo e fair play; mas também de significar pessoa pertencente a níveis elevados na sociedade e até mesmo um membro da pequena nobreza.

Nessa correspondência, um fato, doloroso, chama a atenção. Trata-se do relato da morte de um de seus filhos, Evelyn, um menino de nove anos de idade. Ao contar como tudo se passou, D. Caroline investe longamente na descrição da docilidade e dos interesses dessa criança, dando grande destaque à educação esmerada que ele possuía, detalhe ao qual ela atribuía grande importância, e que representava um símbolo de distinção, como veremos adiante. Ela diz que

Nosso querido era tão inteligente e sensível, tão companheiro de seu pai - mais como um menino de 15 do que de 9 anos de idade. Ele fazia suas lições todas as tardes com Miss Norman, a jovem dama que veio conosco e de quem ele já era aluno na Inglaterra, 
A educação no diário de uma imigrante britânica e em outros escritos na província do Paraná

\& era de fato muito precoce especialmente em decifração. Ele era consideravelmente mais avançado em aritmética do que nossos meninos quando eles saíram da George' com idades de 12 e 15. Ele estava lendo a história popular da Inglaterra de Cassel diariamente e com muito interesse \&, na hora de brincar, os romances de Scott \& poemas \& estava na metade da leitura de Woodstock quando morreu. Uma Bíblia em português, enviada por meu pai, o deliciava particularmente, \& ele lia um capítulo por dia, passando do Português para o Inglês sem referência à Bíblia em Inglês. Ele falava Português lindamente, e quando brasileiros vinham à casa, ele costumava pegar seus livros e mostrar a eles as figuras, explicando-thes os significados. Eles costumavam referir-se a ele como 'aquele ladino' - that sharp one - \& ele era um favorito de todos. Um divertimento que ele gostava muito era jogar xadrex com seus irmãos \& ele também gostava de história natural, particularmente o Treasury of Natural History de Maunders... (TAMPLIN, 1871, p. 1).

Três anos depois dessa perda, morreu seu marido, Charles Albert. Segundo relato da família, a causa de sua morte foi uma profunda tristeza e desapontamento, entre outras razões, pelo modo como foi tratado pelas autoridades brasileiras, que se recusavam a reconhecer oficialmente sua atuação

54 como médico da colônia, função que ele exerceu por um período /Gratificação mensal ao colono Carlos Alberto Templin, servindo como médico na Colônia Assungui, Curitiba. 1873, p. 98; Carlos Alberto Tamplin, colono do Assungui, não tem documentos que comprovem pagamento que requer, Ctba. 1874, p. 157), e, por conseguinte, não o remunerando por trabalhos feitos, queixa muito comum entre outros colonos cujo saber, por notoriamente reconhecido, era aproveitado para suprir as necessidades da precária colônia. Tantas eram as reclamações e denúncias que, chegando ao conhecimento da Rainha Vitória, foi enviado para ouvir os ingleses um Cônsul, Lennon Hunt, cujo relatório de visita submeteu ao Parlamento Britânico em 1875 (MONUMENTA, 1998).

De 1874 a 1880, Caroline permaneceu na colônia e, de acordo com correspondências e relatórios existentes no Arquivo Público do Paraná, ela atuou como professora em escola estabelecida em sua propriedade, The Grange, um lote de pouco mais de seis hectares (62.500 metros quadrados), localizado no núcleo de Turvo, contendo a residência da família, áreas de cultivo e, provavelmente, de pequena criação (porcos e galinhas). Os alunos eram filhos de imigrantes de diversas nacionalidades, além de alguns brasileiros, como se pode deduzir por solicitações que ela fez ao governo provincial 
para que suprisse a escola com livros de diversos idiomas, no que não foi atendida (Pedido de Mme. Tamplin de objetos p/a escola da Col. Assungui, 1875, p. 178). Quando Caroline deixou a colônia em 1880, a escola teve continuidade, sob direção de Miss Julia Norman.

Pouco se sabe da vida privada e das sociabilidades estabelecidas pelos colonos do Assungui, uma vez que os registros encontrados tratam de questões administrativas - são correspondências e relatórios, disponíveis para consulta no Arquivo Público do Paraná. No caso da família Tamplin, tivemos mais sorte, uma vez que, durante a pesquisa, os descendentes no Brasil nos colocaram em contato com descendentes de um neto de Caroline. Professores universitários, residentes no Canadá, disponibilizaram as memórias escritas pelo avô, Sr. Albert Burton, que, ao fazer um balanço de sua vida, referiu-se à sua infância na colônia, onde nasceu e viveu até os seis anos de idade, e de onde saiu com os pais em um processo migratório para a Inglaterra e, depois, definitivamente, para Manitoba, no Canadá. $\bigcirc$ relato de seus primeiros anos, no Assungui, filtrado pelo olhar longínquo e saudoso, transmite uma imagem idílica, difícil de corresponder às condições "reais" da existência das pessoas nas condições precárias que ficaram conhecidas. Marcante no relato do Sr. Albert, entretanto, é a amargura por não ter podido dedicar-se a estudos pelo quais sentiu interesse, e de não ter permanecido na Inglaterra quando criança, para esse fim. Provavelmente, gostava de história, uma vez que, para compor suas memórias, realizou pesquisas, por exemplo, acercado Brasil à época de sua infância. $\bigcirc$ que se apreende da leitura das memórias do Sr. Albert é que, para ele, educar-se significava adquirir qualificações que teriam permitido libertar-se do jugo a que estava sujeito no modo de vida escolhido por seu pai (GILLIES, 2011 ).

\section{Educação e 'para que educar as mulheres' - Inglaterra e Brasil no século XIX}

Este texto não pode deixar de considerar o significado da educação naquelas décadas de fins do século dezenove, quando se anunciava, em alguns lugares, o contexto da Bélle Époque, promovida pelo espírito de pesquisa, de busca do conhecimento, descobertas e invenções, pelo otimismo na ideia de progresso. Brasil e Inglaterra partilhavam, quanto à educação, a mesma cautela em relação à ampliação da educação para os pobres e o 
A educação no diário de uma imigrante britânica e em outros escritos na província do Paraná

mesmo discurso conservador, a mesma preocupação acerca de 'para que educar as mulheres'. Mais ainda, lá e cá, ainda que no Brasil não tão claramente definidas como na Inglaterra, educação e classe social estavam intimamente ligadas. O lugar para as mulheres das classes média e alta era a casa, o lar, submetidas à autoridade do pai e, depois, do marido, e a educação tinha como função a aquisição de adornos, para conquistar um marido e para a vida social; a mulher pobre, por outro lado, se alfabetizada, deveria transmitir os rudimentos dos conhecimentos básicos aos filhos, e também podia trabalhar para contribuir para o sustento da família.

Conforme a Dra. Sara Delamont (1978), do Departamento de Ciências Sociais da Universidade de Cardiff, especialista, entre outros temas, em história da educação para mulheres,

As mulheres de classe média e até certo ponto da classe alta passaram o século dezenove e parte do século vinte tentando redefinir o significado do que é ser ladylike (como uma dama), o que, de acordo com Vera Brittain fez parte do movimento feminista denominado Lady into Woman (De Dama para Mulher), uma frase que capturava os objetivos das feministas para as mulheres de classe média e alta. As mulheres estavam aprisionadas numa existência inútil, de exibição, e as feministas desejavam ser livres e úteis ser mulheres e pessoas/gente. Educação e trabalho eram fatores chave nesta batalha, principalmente educação. Durante a primeira metade do século dezenove, todas as filhas das classes média e alta, exceto em umas poucas famílias não conformistas e intelectuais, recebiam uma educação desenhada para serem inúteis. Elas eram cuidadosamente educadas para serem ornamentais e não para terem qualquer vocação, o que significa que elas não eram educadas nem mesmo para serem boas esposas e mães. Mrs. Grey, uma das figuras chaves no estabelecimento de boas escolas na Grã-Bretanha, expressou isto perfeitamente ao dizer 'Elas não são educadas para serem esposas, mas para arranjarem maridos'. Esta educação inútil consistia em accomplishments (habilidades): noções/rudimentos de línguas estrangeiras, tocar instrumentos e cantar, costura decorativa. Era uma preparação para o flerte, não para o casamento que se esperava obter com isto, apesar de que o papel permitido a mulheres como pessoas adultas era restrito de uma forma que atualmente pareceria inacreditável (DELAMONT, 1978, p. 135). ${ }^{2}$ 
Por outro lado, Franklin K. Prochaska, em sua obra Women and Philanthropy in Nineteenth-Century England (1980), adverte que, embora muitos autores ingleses do século dezenove frequentemente tenham usado a expressão 'natureza e missão' para expressar o que eles acreditavam ser as características das mulheres e as funções que a sociedade as encorajava a assumir, havia, no entanto, tantas missões quanto mulheres. Ou seja, toda mulher, por mais humilde que fosse, tinha uma noção da individualidade de suas circunstâncias e das suas obrigações cotidianas. Isto não quer dizer que elas podiam fazer o que desejassem independentemente das leis e do costume, uma vez que a sociedade impunha severas limitações às mulheres, muitas das quais persistiram longamente. Porém, muitas mulheres, surpreendentemente, e não apenas das classes média e alta, conseguiram viver vidas independentes, apesar do peso das convenções. Havia uma pressão para que elas sofressem caladas, o que não significa que assim procediam. Em relação às mulheres daquele tempo, alerta Prochaska, temos que levar em consideração que, em situações nas quais tendemos a ver apenas limitações, pode ser que elas vissem possibilidades. Alguns fatores promoviam mudanças: a vida na cidade era menos doméstica do que no campo; a vida social tornava-se mais pública; grandes levas de mulheres das classes populares passavam a trabalhar nas indústrias; mulheres das classes médias abastadas passaram a ter mais tempo disponível, inclusive pela disponibilidade de serviçais para cuidar de suas casas e de seus filhos; e um grande número de mulheres excedentes/redundantes, como eram consideradas as que ficavam solteiras e as viúvas sem posses, precisavam encontrar alguma forma de ocupação. Entre essas, as únicas ocupações consideradas respeitáveis eram as de professoras ou governantas, sendo a segunda um tanto ambígua, pois, se antes fora uma lady, agora incompatibilizava aquele status ao ser paga como qualquer outro serviçal. De uma forma ou de outra, era a educação que as qualificava para essas posições.

No Brasil, educação era a prerrogativa daqueles que a tinham assegurada pelos benefícios trazidos pelo nascimento ou posição. Até 1877 , estimava-se que apenas 1.563 .000 pessoas livres sabiam ler e escrever, enquanto 5.580.000 pessoas livres de mais de cinco anos de idade não o sabiam. Apenas 170.000 crianças frequentaram a escola. Escolas secundárias eram raras e mal dirigidas, com exceção de uma instituição modelo no Rio de Janeiro - o Colégio Pedro II (GRAHAM, 1968 apud GILLES, 1998, p. 14). 
No Paraná, os discursos oficiais a respeito da importância da educação apareceram já nos primeiros momentos da emancipação em 1853. Quando foi transformada em capital da Província do Paraná, pela lei de 26 de julho de 1854, Curitiba possuía somente duas escolas de primeiras letras para meninos e uma para meninas. $\bigcirc$ Conselheiro Zacarias de Goes e Vasconcelos, primeiro presidente da província, defendeu a necessidade de mais escolas para meninas. Disse ele que instruílas significava, de algum modo, criar uma escola em cada família, visto que eram muito raros exemplos de mães que soubessem ler e escrever, cujos filhos, se por alguma circunstância deixassem de frequentar a escola, não soubessem também ler e escrever, já que elas, em suas horas vagas, à custa de todo o sacrifício, ensinariam a eles aquilo que aprenderam. Em 1856, subiu para cinquenta o número de escolas primárias entre públicas e particulares, sendo quinze femininas e trinta e cinco masculinas. Das femininas, catorze eram públicas e uma particular. Das masculinas, vinte e seis eram públicas e nove particulares (Relatório Apresentado à Assemblea Legislativa Provincial do Paraná no dia $1^{\circ}$ de março de 1856, pelo vice-presidente em exercício, Henrique de Beaurepaire Rohan apud GILLIES, 1998).

58 Outra figura que no Paraná ocupou-se da valorização da escolarização foi o Engenheiro de Obras e, posteriormente, vice- presidente da província, Henrique de Beaurepaire Rohan. Ele relatou que, em suas viagens pelo interior, constatou que todos gostariam de estudar, mas, para os mais pobres, uma das dificuldades era a locomoção. A solução que ele daria seria a criação de internatos, segundo disse, de tal modo constituídos, que pudesse o menino, a par da instrução que recebesse, entregar-se a algum trabalho produtivo, que salvasse de alguma sorte as despesas do estabelecimento, e tivesse ainda mais a vantagem de o dispor para qualquer ramo da 'indústria'. De fato, ao longo de sua vida política, inclusive entre as soluções em face da abolição, defendeu veementemente o que hoje chamaríamos de uma 'educação profissionalizante', para toda a população livre, inclusive para os ingênuos, pois, para ele, esta seria mais útil do que formar homens instruídos nas letras, voltados à contemplação e à metafísica (GILLIES, 2002). Logicamente, por trás disto está uma organização do mundo do trabalho e uma "reforma" conservadora, que distribui e mantém os papéis e as funções conforme o pertencimento social.

Também o preocupava o modo de ensinar crianças a ler, utilizando, para tal fim, cartas particulares, que elas levavam para a escola a pedido de 
seus mestres. Além da inconveniente indiscrição em relação à privacidade que deveria ser resguardada, ele observou que essas cartas eram geralmente repletas de erros de ortografia e de uma gramática estropiada. E, por fim, lamenta que não houvesse na província os meios necessários para dar às meninas a instrução "[...] que mais thes conviria [grifo meu], essa educação, que deve ser o predicado de boas esposas e de boas mães de família". Naquele início da segunda metade do século dezenove, havia somente uma escola secundária particular para meninas em Paranaguá, fundada por duas americanas - Jessica e Willie James (WESTPHALEN, 1973 apud OLIVEIRA, 1986).

Nas décadas seguintes, à medida em que os migrantes iam chegando à província, novas classes de turmas foram sendo abertas, e quando D. Caroline Tamplin mudou-se para a capital, já havia lá um público interessado em receber aulas particulares, e algumas escolas nas quais a pessoa qualificada podia candidatar-se a ensinar. De tal modo que, antes de deixar a colônia, em abril de 1880, um anúncio é publicado no periódico Dezenove de Dezembro, nos seguintes termos:

\section{CAROLINE TAMPLIN}

Ex-professora da colônia Assunguy, dá lições de piano, canto, francez, inglez, geographia, desenho e prendas domésticas, em casas particulares. Póde ser procurada a rua do Sottomaior, em casa de seu filho, o negociante Alberto Tamplin. Discípula de Thalberg, chama em seu apoio o testemunho dos distinctos professores dessa capital, cujo acolhimento e aplauso the têem sido por vezes tão lisonjeiramente grato. Seus pequenos dotes e conducta moral receberam sempre, em sua pobreza e viuvez, a proteção dos honrados administradores desta província, assim como dos dignos directores e virtuoso parocho de sua colônia (D. CAROLINE TAMPLIN, 1880, p. 4).

Evidências indicam que D. Caroline Tamplin foi bem-sucedida na obtenção de alunos, ainda que inconstantes, e que foi bem recebida nos círculos familiares e sociais da capital paranaense, não sem enfrentar desafios - ocasionais intrigas. E, acima de tudo, a mentalidade conservadora manifestada e continuamente reafirmada publicamente, entre outras maneiras, por intermédio da publicação de artigos preocupados em doutrinar leitores quanto aos papéis da família e da mulher. 
A educação no diário de uma imigrante britânica e em outros escritos na província do Paraná

$\bigcirc$ ano de 1884 é particularmente produtivo nesse sentido, pois, a partir do mês de janeiro, o periódico Dezenove de Dezembro passou a publicar uma série de textos acerca da mulher - sua natureza, seu papel, suas capacidades, o que ela representa no mundo e o que ensinar-the, no caso de procurar uma educação formal.

Assim, no dia 3 de janeiro de 1884, na seção Variedades, um autor, cujo nome não é citado, comenta que, além de momentos ou épocas históricas, havia uma mulher universal, de traços fixos, imutáveis, uma mulher que "[... diviniza-se sempre, ainda que não se compreende jamais, quer se chame Cleopatra ou Lucrecia; quer roube ao homem os pensamentos como Madame de Stäel ou the usurpe seu traje como Jorge Sand". E continua:

Há coisa alguma mais imcomprehensível, mais mysteriosa, que esse ser mescla confusa de aspirações boas e más, de generosos impulsos, e de triviais affeições; esse ser que revestido de galas de formosura, rodeado d'essa aureola de pureza e de encanto que traz cingido á sua cintura o desvario do homem, forma uma parte a mais considerada, sem dúvida, nas nossas modernas sociedades? Ser que nasce escravo e cobra tributos á liberdade; que cresce para fazer nossas horas doces e serenas; que morre alfim, levando para o seu tumulo a nossa felicidade. [...] Vede-a: débil por natureza, apresenta-se nos para nos desmentir a Maria Corouel, Joanna D'Arch, Maria de Padilha; tímidas por cálculo não se envergonham de ostentar nas suas paginas os nomes de Judith, Dalila, Margarida de Borgonha; incrédula por costume, orgulha-se ainda com as recordações de Safo, Eloise, Santa Thereza. Victima umas das paixões mundanas; escravas outras d'uma virtude de que ninguém lhe conta; sujeita a última á atração d'um amor infinito, eterno, porque não era humano (A MULHER - DE RELANCE, 1884, p. 3).

Sendo esta a natureza da mulher, para que educá-la?

Há uma preocupação muito arraigada acerca da educação da mulher: desde os seus primeiros annos educa-se a mulher para que brilhe, não para que pense; ensina-se the a arte de agradar, não a de viver [...] Um dia chegará, anunciado já por alguns profundos pensadores, em que a mulher será o que deve ser: a estrella mysteriosa que alumia os destinos do homem, que the inspira os mais elevados pensamentos, as mais sublimes concepções (A MULHER - DE RELANCE, 1884, p. 3). 
Embora pareça que o autor acima esteja advogando um outro tipo de educação à mulher que não a praticada, em 19 de fevereiro ele escreve, concluindo uma diatribe, que "[...] da educação das mulheres depende a verdadeira felicidade dos homens". É que, dez dias antes, num domingo, havia sido publicado que

Ora, tanto as mulheres são geralmente inábeis para compreender, e impróprias para utilizar as especulações scientíficas, quanto a sua inteligência se presta a aprender e admirar tudo o que nas sciencias se apresenta sob uma forma: os fatos e os homens. Ensine-se-lhes portanto o necessário apenas de mathematica para apreciarem os resultados da sciencia, os benefícios da sciencia, os heroes da sciencia (COMO SE DEVEM EDUCAR AS MULHERES, 1884, p. 2).

Portanto, a educação "apropriada" era aquela que deixasse claro o que era considerado o papel adequado de cada um, "[...] de acordo com sua natureza $[\ldots]$ ", conforme tema (SEMELHANCCAS DA MULHER COM A NATUREZA, 1884, p. 31 do dia 26 de março de 1884. Esses monólogos se prolongam ao longo dos meses e anos, e, em 14 de abril de 1886, Pamphilo d'Assumpção (QUESTÕES SOCIAIS. NOVIDADES DA ÉPOCA, 1886, p. 2-3) - que foi aluno de pintura de Caroline e, anos mais tarde, ao se formar pela Faculdade de Direito de São Paulo, tornou-se o primeiro presidente do que viria a ser a seção paranaense da Ordem dos Advogados do Brasil -, fez longo discurso contra a emancipação feminina, o voto, o estudo com vistas a um título científico, contra a ocupação de empregos públicos ou de lugares que fossem "[...] inteiramente incompatíveis com a sua natureza facilmente maleável [...]" e que levariam a que fossem abertas "[...] as portas, dando livre acesso ao mal da sociedade", pois, levariam "[...] o vírus destruidor ao seio da família que é o fundamento de todo o organismo social". E, dando andamento a essa política de gênero, entre os meses de maio e junho, o Dezenove de Dezembro publica artigos com o título "Lições de Philosophia Moral", escritos por Paulo Janet, nos quais discute, entre outros temas, a vida da família, "o chefe da família - o marido", sob cujo título discute: a autoridade da família - se é necessária e a quem pertence, afirmando que "ao homem... pela superioridade da força e da razão"; faz a comparação da razão do homem e da mulher; fala dos deveres do marido: "proteção e fidelidade" e, em junho, trata do tema "a dona de casa - a mulher". 
que pretendemos aqui não é uma mera relação do que o periódico estava publicando relativamente às relações de gênero, mas problematizar o empenho realizado nas décadas finais do século dezenove em reação ao comportamento das mulheres que, diferentemente da generalização predominante em parte da literatura ficcional e científica, não era assim tão submissa a essa ordenação desejada pelos homens. A perspectiva adotada neste texto é aquela que procura desnaturalizar os discursos acercados papéis atribuídos pela ideologia judaico-cristã aos gêneros masculino e feminino, entendendo-os, outrossim, como "[...] uma maneira de referir-se à organização social da relação entre os sexos" (SCOT, 1990, p. 2 e 7). Interessa-nos, portanto, identificar as "construções sociais", a "[...] construção inteiramente social das ideias sobre os papeis [considerados] próprios aos homens e às mulheres".

Em um artigo a respeito dos papéis de cada gênero na Inglaterra do século dezenove, Kathryn Hughes (s.d.) explica que, na época vitoriana, o papel do homem e da mulher foi mais rigorosamente definido do que em qualquer outra época histórica. Em períodos anteriores tinha sido comum que marido e mulher compartilhassem algumas funções, e não era incomum, por exemplo, que o casal, tendo uma loja com a casa instalada no andar de

62 cima, a mulher pudesse cuidar dos afazeres domésticos e, ao mesmo tempo, atender clientes, encarregar-se da contabilidade etc., aos moldes das discussões que Catherine Hall empreende em seu Sweet Home (1991). Mas, a partir de 1830, esse tipo de parceria mudou, e as esferas se definiram com o aumento dos recursos que permitiram que a casa e a loja fossem localizadas em espaços diferentes e distantes um do outro - à mulher, a casa e a família; ao homem, os negócios, a vida pública.

A ideologia das 'esferas separadas' baseava-se numa definição das características "naturais" de homens e de mulheres. As mulheres eram consideradas fisicamente mais fracas, mas moralmente superiores aos homens, explica Kathryn Hughes (s.d), o que significava que elas seriam mais adequadas para a esfera doméstica, responsáveis por preparar a próxima geração para dar continuidade àquele modo de vida. No entanto, o fato de elas terem tamanha influência em casa, no lar, era usado como argumento para não conceder-thes o direito ao voto.

Como podemos observar, a relação entre educação e gênero no Brasil e na Inglaterra apresentam semelhanças. No artigo de 3 de janeiro de 1884 do Dezenove de Dezembro (p. 3), o autor, cujo nome não vem publicado, 
argumentou que a mulher possuía uma missão civilizadora, qual seja, a de "[...] levar a paz e a consolação aos opprimidos e aos tristes; unir com laços indissolúveis tudo o que é ephemero e escorregadio, restaurar, de acordo com o homem, o encantado alcançar das esperanças [...]". Isto mais parece uma cópia de algo que foi publicado na Inglaterra sob o título Woman's Rights (Os Direitos da Mulher), e que, por estar na forma de pequenos versos, facilitaria a doutrinação da mulher, metodologia comum na Inglaterra, inclusive para educar crianças.

O direito de ser confortadora, quando todos os outros confortos falharem; o direito de animar corações desfalecidos, quando os problemas o assaltarem; o direito de treinar a mente infantil, a pensar no cév e em Deus; o direito de guiar os passos dos pequeninos, pelo caminho que trilhou nosso Salvador; o direito de consolar os aflitos, e de secar as lágrimas dos enlutados; o direito de oferecer abrigo aos oprimidos, e gentilmente censurar temores; o direito de ser um brilhante raio de sol, no lar humilde ou na mansão; o direito de sorrir com amor esplendoroso, e apontar as alegrias que virão; o direito de secar a fronte febril, aliviar a mente agitada; e gentil e suavemente dizer 'todos que procurarem, encontrarão'. Tais são os mais nobres direitos da mulher, os direitos que Deus deu, o direito de confortar o home na Terra, e suavizar sua estrada para o Céu. M.C.M.R. (HUGHES, s.d.). ${ }^{3}$

Este é o contexto cultural em que se insere D. Caroline Tamplin e sua família, ao deixar a Inglaterra para se estabelecer no Brasil.

Um dado interessante que aproxima contextos tão diferentes em alguns aspectos é o papel da religião na formação de condutas e de papéis desejados como ideais, lá e cá. Catherine Hall ( 1991 ) problematizou em seu estudo como, por meio da ação de evangelistas, procurou-se, na Inglaterra, doutrinar a classe trabalhadora para os hábitos considerados ideais de serem adotados por aqueles de quem se desejava equilíbrio, constância e com os quais se pudesse contar, ou seja, que fossem portadores de reliability (confiabilidade). Aquele esforço empregado por determinadas pessoas que a autora cita pode ser entendido como a consciência de que, para que a fábrica funcionasse, era preciso que os homens não bebessem e comparecessem ao trabalho todas as manhãs, e que as mulheres, ficando em casa, mantivessem a ordem e educassem os filhos no sentido de reproduzirem neles um caráter portador dessa 
'qualidade', desse compromisso. Afinal, tratava-se de estabelecer e manter a distribuição dos papéis no não tão novo modo de produção.

No Brasil, os discursos citados podem ser mais bem entendidos, devido à forte influência da Igreja Católica no âmbito do Estado, da educação, dos modos de pensar e de viver naquela época. Era a hegemonia católica que orientava fortemente as ações nas esferas pública e privada. Por outro lado, a chegada contínua de imigrantes europeus, grande parte dos quais era protestante, obrigou o Estado a concessões aos novos tipos de fiéis. Em 11 de setembro de 1861, foi publicado o Decreto $n^{\circ} 1.144$, e em 17 de abril de 1863, o Decreto $n^{\circ} 3068$, estabelecendo direitos aos protestantes, autorizando seus ministros a celebrar casamentos com efeitos legais, e regulamentando os direitos civis dos filhos de protestantes, os registros de óbitos e o sepultamento de protestantes em lugar apropriado. Apesar disto, na colônia Assungui, por exemplo, não havia cemitério protestante, e quando, primeiro em 1869, e depois, em 1871, D. Caroline perdeu seus filhos Lionel e Evelyn, essas crianças tiveram que ser sepultadas num canto do jardim, um pouco distante da residência. Além disso, os services, ou seja, aquilo que seriam as missas católicas de domingo, para os protestantes, naqueles tempos, e no caso 64 dos Tamplins no Assungui, eram realizados em casa. Caroline conta na carta à cunhada como a criança falecida, cantava lindamente, como um anjo, nessas ocasiões.

Na documentação provincial relativa à família Tamplin, uns aparecem como católicos, outros como protestantes e somente, aos poucos, esse quadro vai ficando mais nítido, a partir do envio recente, por um membro da família Tamplin, na Inglaterra, da certidão de casamento de Charles Albert e Caroline. Eles se casaram na St. Pancras Church, pertencente à paróquia de St Pancras, condado de Middlesex, em 18 de setembro de 1851. $\bigcirc$ site da paróquia define-a como sendo

Uma dinâmica/próspera igreja paroquial de tradição anglo-católica pertencente à lgreja da Inglaterra que, embora orgulhosos de nossa história, estamos totalmente presentes como parte de uma comunidade vibrante e diversa de devotos que anunciam as boas novas de Jesus Cristo. Há incenso e pregações animadas nas nossas missas nas manhãs de domingo e uma animada lgreja Junior (PARISH OF OLD ST. PANCRAS, s.d.). ${ }^{4}$ 
Ao longo dos anos, alguns da família Tamplin aparentemente podem ser apontados como protestantes, como foi o caso da filha mais nova de Caroline, Alberta, que se casou com um rapaz da família Mason, e, uma vez falecidos, ambos foram sepultados no Cemitério Protestante de Curitiba, cuja lápide ainda hoje se conserva preservada pelos familiares. Já Caroline e seu filho Frederick optaram por frequentar a lgreja Católica. Não foram encontrados registros de algum rito de passagem oficial, indo da lgreja Anglicana para a Apostólica Romana. Mas, os registros no Diário de Caroline, datados do mês de dezembro de 1881 , dão conta da dedicação do filho ao estudo do catecismo, aos quinze anos de idade, à ida de mãe e do filho a várias missas, chegando a três num mesmo dia, à crisma de ambos e ao cultivo de amizade com padres e até com o Bispo, que chegou a visitála em casa. De fato, seus dias se passavam numa rotina intercalada entre as aulas particulares, os cuidados para com os filhos, as visitas recebidas e as retribuídas e as idas à igreja. Seu Diário configura, assim, uma memória de trabalho, de sociabilidades e de devoção.

A religião e a possível conversão de Caroline possuem ainda um outro caráter, o do preenchimento de requisitos para poder ensinar. Conforme Maria Cecília Martins de Oliveira (1 986), em estudo acerca dos imigrantes e o ensino na província do Paraná, o primeiro regulamento de ensino, de 1857, apresentava provisões para a atuação de professores estrangeiros, estabelecendo como requisitos capacitação profissional e boa conduta moral e cívica. Quanto ao aspecto religioso, exigia-se apenas que, havendo nas escolas não católicas alunos católicos, estas deveriam ter um professor da religião, que era a do Estado, sob pena de multa e de fechamento do estabelecimento. No entanto, um outro regulamento, de 1871, estabeleceu critérios para a admissão de professores, tanto no ensino público quanto particular, sendo que "[...] indivíduo não católico, ou que não tivesse sua cidadania regularizada, ficava impedido de assumir funções junto ao magistério primário ou secundário" (OllVEIRA, 1986, p. 55-56). A mesma autora traz uma citação em que "Mme. Tamplin, professora da escola do Turvo, mantida pelo governo geral, salientava a necessidade de criação de duas escolas promíscuas na sede do povoado, além de um asilo para os filhos dos colonos pobres e meninas desamparadas". Tal informação, tendo sido extraída de um relatório da colônia Assungui ao presidente da província, Lamenha Lins, em 1876, é um indício 
de que o catolicismo apostólico romano já era, à época, a fé professada por D. Caroline.

\section{A experiência de Caroline Tamplin em Curitiba na década de 1880}

Ao mesmo tempo que se transferia para Curitiba, D. Caroline registrava em um diário, representado por um caderno comprado da W.H. \& S. de Londres, conforme aparece na página frontal, uma seleção daquilo que considerou importante no seu cotidiano, ao longo dos anos de 1880 a 1882. Suas anotações, outrossim, não têm o caráter íntimo ou confessionário de um outro gênero semelhante, o diário íntimo, mas se inserem nas chamadas escritas femininas e de foro privado. São registros feitos por uma mulher singular em seus esforços diários para se manter e aos filhos com um padrão de vida civilizado, com a preservação de hábitos cotidianos, muitos dos quais praticados em Londres à mesma época (GILLIES, 2014). Caroline Tamplin trazia introjetados em si, em cada ato dos seus dias, práticas e valores que, dadas as

66 circunstâncias em que se encontrava, alguns poderiam até considerar fora do lugar. Mas a disciplina para apresentar uma imagem cuidadosamente elaborada, um padrão de conduta controlada e ideal, segundo o que Norbert Elias (1993) chamou de processo civilizatório, foi, entre outras razões, a maneira que ela, uma outsider, encontrou para se inserir e se manter nos círculos dos estabelecidos na sociedade curitibana. A educação dos modos para aquisição de boas maneiras, a educação formal, recebida na escola ou em casa com tutores, e a educação intelectual, por intermédio do cultivo de si pela leitura e pelo aprendizado de outros idiomas compuseram os sinais de sua distinção. Registros em seu diário indicam que isso era significativo para ela. Ainda que viúva e de meia idade, mas mulher só, não escapava ao escrutínio da pequena sociedade provinciana. Possuía, no entanto, um capital cultural que excedia a normalidade encontrável entre os habitantes do lugar àquela época, o que, se de um lado podia causar inveja e reservas de uns, também podia despertar o respeito de outros. Essa característica ficou evidente pela maneira como passou a transitar entre os círculos familiares e sociais a partir do exercício da ocupação que abraçou, como professora, e dos atributos resultantes de uma educação permanente. 
Caroline trabalhava muito. Na verdade, era quase compulsiva a maneira como se mantinha ocupada, como se a contabilidade das horas tivesse sempre que resultar em saldo positivo, este significando a estrita observação e aproveitamento útil do tempo. Quando não eram as aulas fora de casa, eram as que ela dava para os filhos, ou as leituras e outras tarefas que ela determinava para eles: aulas de francês, italiano, pintura, desenho, música, leituras em voz alta, o catecismo, a leitura da Bíblia. Muitas vezes, essas aulas aconteciam muito tarde da noite, mesmo após exaustivos dias de trabalho. $\bigcirc$ ócio não tinha espaço em suas vidas; até as visitas e passeios, tudo fazia parte de uma maneira de viver rigorosamente observada.

Sua vida era marcada pela alternância das estações do ano, climáticas e sociais. O tempo determinava os limites do possível, aproximava ou afastava as pessoas umas das outras, determinava seu recolhimento e suas atividades: trabalho e passeios no tempo bom, alternado por mais leituras, pinturas e trabalhos de agulha nos dias frios e chuvosos, embora seja notável a tendência gregária dos personagens dessa história. Um dos fatores que provam essa dedução baseia-se no próprio interesse em aprender outros idiomas. Sua utilidade não era, como nos dias atuais, acrescentar ao currículo de habilidades apropriadas para o mundo do trabalho, mas tinha um caráter social e cultural importante, ou seja, a formação de um roll de habilidades apropriadas para a sociabilidade. $\bigcirc$ mesmo pode-se afirmar do interesse em aprender canto e piano.

número de eventos sociais que ocorriam na cidade, de caráter público e privado, indica a utilidade do aprendizado, que vai além da ornamental. Possuir essas competências sociais viabilizava a entrada no grupo dos estabelecidos, e circular entre eles certamente representava, para uma senhora viúva que dependia do seu trabalho como professora, uma importante credencial para obter alunos e frequentar suas casas. Os registros indicam que essa distinção foi conferida a D. Caroline. Um exemplo disso, e que acontecia com frequência, foi quando os Fonsecas mandaram buscá-la, pois estavam recebendo em sua casa o presidente da Província, Carlos Augusto de Carvalho. D. Caroline registra que, no dia 18 de abril de 1882, uma quarta-feira, "No fim da tarde, D. M. Fonseca mandou convidar-me para jantar, pois o Presidente Dr. Carvalho estava lá, \& eu o achei muito simpático - Toquei duas sonatas de Beethoven - Pathetique \& Op 31 n 3" In the evening, D. M. Fonseca sent to invite me to tea, the Pres.t Dr. Carvalho being there, \& I found him very friendly 
- Played two sonatas of Beethoven - Pathetique \& Op $31 n^{\circ}$ 3). Uma outra ocasião social de grande destaque da qual Caroline participou ativamente ocorreu quando foram oferecidas soirées em homenagem ao Conde d'Eu e à Princesa lzabel, em visita à Província do Paraná, em dezembro de 1884.

Também o teatro e o aprendizado de desenho e pintura faziam parte dos interesses da época. Nessa última atividade, receberam bastante destaque, no Dezenove de Dezembro de março de 1885 e de fevereiro de 1888 , os quadros pintados pelos irmãos Paulo e Pamphilo Assumpção. Em uma dessas datas, por ocasião da abertura da exposição das obras pintadas por eles, foi prestada larga homenagem à mestre, D. Caroline Tamplin. Os moradores de Curitiba, brasileiros e/ou estrangeiros, cultivavam esses prazeres, e também o hábito da leitura. Havia teatros e clubes literários, entre os quais em um foi introduzido seu filho Frederick (Fritz), bem como a circulação de livros passados entre amigos. Os registros no diário indicam que havia uma 'rede de leitores' em Curitiba, ou seja, um grupo de pessoas que, tendo tido acesso a determinados livros, liam e, depois, emprestavam a seus amigos. Entre os maiores colaboradores a essa 'biblioteca circulante' estavam Mrs. Withers e Dona Thecla. Elas liam Lady Georgiana Furlleton, Mrs. Oliphant e Richard Burton. De

68 Mrs. Oliphant, circulava o livro Life of a Queen. $\bigcirc$ interessante é que, tendo sido escrito ou publicado em 1880, em maio de 1881 já está sendo lido na província, também por Caroline, que registrava em seu diário títulos e/ ou autores como: $\bigcirc$ mestre de Golgotha, Fille Mauditte, Revolt de La Vendée, Midshipman Easy, Rookwood, Valentine Vox. Para os filhos, Cinco Milhões da Begum, Highlands of Brazil; para ela, DrisBig Ayussinyan Bszringa, de Schiller. E History of Italy, de Guscerardini; Paraguayan War, Atala, Publicans \& Sinners, Wunderfamos Gofessatsstan, Wanderers in Trinidad \& on the Orinoco, Fabiola, Waldinsens, Jeune Anach.ses, Sombra e Luz, Ride to Khiva, Portugal na Balança da Europa, Wild Scenes in Columbia e Wunderbar Erzahlungan. $O$ interesse por esses temas e o registro desses títulos devem representar ou ter tido o intuito de representar alguma coisa.

Os últimos vestígios de D. Caroline Tamplin datam de 1888. Em estudo realizado acercadas mulheres curitibanas a partir de 1889, Etelvina Maria de Castro Trindade (1996) identifica um contexto em que a mulher vem à cena "apresentando mil faces e múltiplos contornos", e que são, ao mesmo tempo, figura doméstica e dama social. À mulher de família, "a educação acrescenta uma face externa treinada para a vida social e para os campos, 
ainda que limitados, do trabalho", mas, vai-se estruturando um ensino que, a despeito da laicidade proclamada pelos ideais republicanos, insere princípios religiosos nos programas escolares, e preserva a ideia de que a boa formação da mulher deve caracterizar-se pela irradiação da fé, da virtude e moralidade cristãs, desenvolvendo e fortalecendo nela a disposição ao sacrifício, à disciplina, renúncia, modéstia, docilidade, doçura e bondade, voltando-se ela "[...] ao bem dos demais - uma mulher de vivência interior, alheia às próprias necessidades [...]" - qualidades consideradas indispensáveis à felicidade de um lar (TRINDADE, 1996, p. 38), bem aos moldes do poema dirigido às mulheres inglesas, reproduzido em páginas anteriores.

\section{Considerações finais}

A título de conclusão, acredito ser possível propor que D. Caroline Tamplin não era insensível à sua condição peculiar - estabelecida, outsider ou nas margens? - e que, a despeito de ser a escrita de diários uma prática disseminada entre os ingleses, ao menos desde o século XVIII, percebe-se, num universo tão repleto de desafios e perigos, que deve ter sido uma das razões para o registro de fragmentos selecionados do seu cotidiano que contribuíssem para a construção de uma imagem, uma identidade de si, algo que a representasse em sua ausência, e que fosse também como uma prestação de contas. Nesse sentido, a representação que se obtém dela, resultante da leitura e análise dos documentos utilizados neste texto, é de uma mulher portadora de considerável capital cultural, no qual ela investia como um processo de educação permanente.

A propósito da escrita produzida por D. Caroline Tamplin, é importante destacar a relevância de diários, memórias, cartas, entre outros documentos que podem compor arquivos pessoais, para a tessitura da história. Produzidos no âmbito do privado e acrescidos de outros vestígios do passado, como jornais e periódicos, por exemplo, contribuem para a construção de um conhecimento do cotidiano de indivíduos e do contexto social, político, econômico do qual fizeram parte.

Quanto à educação para as mulheres, na Curitiba da segunda metade do século XIX, os registros no diário de D. Caroline Tamplin, por um lado, e os artigos publicados pelo periódico Dezenove de Dezembro aqui citados, além 
A educação no diário de uma imigrante britânica e em outros escritos na província do Paraná

de outros contendo anúncios de escolas para meninas, ao longo da década de 1880, são indícios de que a educação feminina estava em pauta, na frequência escolar pública e privada, e nos discursos interessados em cerceá-las. Esses dados indicam que as mulheres vinham se manifestando no sentido de romper os limites a elas impostos e de conquistar uma cidadania plena.

\section{Notas}

1 Trata-se, possivelmente, da St. George's Boy School, uma all boys boarding school Internato só para meninos), que existiv em Ramsgate, uma pequena cidade no condado de Kent, Inglaterra, entre 1800 e 1875 .

2 No original: [...] the ladies of the middle, and to some extent, the upper classes, spent the nineteenth century and much of this ne trying to redefine being ladylike: Vera Brittain's account of the feminist movement is called Lady into Woman, a phrase which captures the feminist's aims for the middle-class and upper-class women. Ladies were imprisioned in a showy, useless existence [...], (DELAMONT, 1978, p. 135).

3 The right to be a comforter, when other comforts fail; the right to cheer the drooping heart, when troubles most assail. The right to train the infant mind, to think of Heaven and God. The right to guide the tiny feet, the path our Saviour trod. The right to solace the distressed, to wipe the mourner's tear [...] M.C.M.R. (HUGHES, s.d.).

704 No original: [...] it is a thriving parish church in the Anglo Catholic tradition of the church of England. Whilst being proud o four history, we are fully present as part of a vibrant and diverse worshiping community making known the Good News of Jesus Christ. There is incense and lively preaching a tour Sunday morning mass and a thriving Junior Church [...] (PARISH OF OLD ST. PANCRAS, s.d.).

\section{Referências}

ARTIÈRES, Philippe. Arquivar a própria vida. Tradução Dora Rocha. Revista Estudos Históricos, Rio de Janeiro, v. 11, n. 21 , p. 9-34, jul. 1998.

BRASIL. Decreto $\mathbf{n}^{\circ} \mathbf{1 . 1 4 4}$, de 11 de setembro de 1861. (Coleção de Leis do Império do Brasil, p. 21, v. 1, p. 1, 1861) Disponível em: http://www2.camara.leg.br/legin/fed/ decret/1824-1899/decreto-1 144-11-setembro-1861-555517-publicacaooriginal-74767-pl.html. Acesso em: 14 jan. 2017.

BRASIL. Decreto $\mathbf{n}^{\circ} \mathbf{3 . 0 6 8}$, de 17 de abril de 1863. (Coleção de Leis do Império do Brasil, p. 85, v. 1, 18631. Disponível em: http://www2.camara.leg.br/legin/fed/ decret/ 1824-1899/decreto-3069-17-abril-1863-555008-publicacaooriginal-74026-pe. html. Acesso em: 14 jan.2017. 
D'ASSUMPÇÃO, Pamphilo. Questões Sociais. Novidades da Época. Dezenove de Dezembro, Curitiba, p. 2-3, 14 abr. 1886.

DELAMONT, Sara. The contradictions in ladies' education. In: DELAMONT, Sara; DUFFIN, Lorna (Ed). The Nineteenth-Century Woman: her cultural and physical world. London, 1978, p. 134-163. Disponivel em: https://books.google.com.br/books?id=hvOłORvQwMgC\&p $g=P A 134 \& \mathrm{lpg}=$ PA $134 \& \mathrm{dq}=$ sara+delamont+the+contradictions+in+ladies+education \&sourc

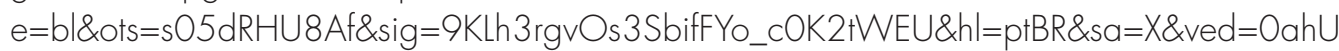
KEwiMILnFx4XQAhWFEpAKHRoPCVOQ6AEIKDAC\#v=onepage\&q=sara\%20delamont\%20 the\%20contradictions\%20in\%20ladies\%20education\&f=false. Acesso em: 30 out. 2016.

D. CAROLINE TAMPLIN. Dezenove de Dezembro, Curitiba, p. 4, 17 abr. 1880.

A MULHER (De Relance). Dezenove de Dezembro, Curitiba, p. 3, 3 jan. 1884.

AS MULHERES. Dezenove de Dezembro, Curitiba, p. 3, 19 fev. 1884.

SEMELHANÇAS da Mulher com a Natureza. Dezenove de Dezembro, Curitiba, p. 2, 26 mar. 1884.

QUESTÕES SOCIAIS. Novidades da Época. Dezenove de Dezembro, Curitiba, p. 2-3, 14 abr. 1886.

A FAMÍlIA - Lições de Philosophia moral - A vida da família. Dezenove de Dezembro, Curitiba, p. 2, 19 maio 1884.

ELIAS, Norbert. O processo civilizador. Tradução Ruy Jungmann. Rio de Janeiro: Zahar, 1993.

GILLARD, Derek. Education in England: a brief history. In: Education in England. The history of our schools, 2011 . Disponivel em: http://www.educationengland.org.uk/history/chapter02.html. Acesso em: 30 out. 2016.

GILLIES, Ana Maria Rufino. Henrique de Beaurepaire Rohan: razão e sensibilidade no século XIX. Curitiba, 1998. 109f. Monografia (Graduação em História) - Universidade Tuiuti do Paraná, Curitiba, 1998.

Políticas públicas e utensilagem mental: uma análise das reformas propostas por Henrique de Beaurepaire Rohan em 1856 e 1878. 2002. 130f. Dissertação (Mestrado em História) - Programa de Pós-Graduação em História, Universidade Federal do Paraná, Curitiba, 2002. 
A educação no diário de uma imigrante britânica e em outros escritos na província do Paraná

As memórias de um senhor britânico sobre sua infância na colônia do Assunguy (Paraná), Inglaterra e Canadá na segunda metade do século XIX: migrações, memórias e identidades. In: SIMPÓSIO NACIONAL DE HISTÓRIA - ANPUH, 26; 201 1, São Paulo. Anais... São Paulo: Universidade de São Paulo, 2011.

O diário de uma imigrante britânica no Paraná (1860-1890): memórias, trabalho e sociabilidades. Curitiba: SAMP, 2014.

HALL, Catherine. Sweet home. In: PERROT, Michelle (Org.). História da Vida Privada: da Revolução Francesa à Primeira Guerra Tradução Denise Bottmann e Bernardo Joffily. São Paulo: Companhia das Letras, 1991. ().

HUGHES, Kathryn. Gender roles in the 19th century. In: Discovering Literature: romantics and Victorians. s.d. Disponível em: British Libary. https://www.bl.uk/romantics-and-victorians/articles/gender-roles-in-the-19th-century. Acesso em: 30 out. 2016.

JANET, Paulo. A FAMÍlIA - Licções de Philosophia Moral. A vida da família. Dezenove de Dezembro, Curitiba, p. 2-3, 19 maio. 1884.

MARSH, Jan. Gender Ideology \& Separate Spheres in the 19th Century. s.d. Disponivel em: http://www.vam.ac.uk/content/articles/g/gender-ideology-and-separate-spheres-19th-

72 -century/. Acesso em: 30 out. 2016.

OlIVEIRA, Maria Cecília Marins de. Os imigrantes e o ensino na Província do Paraná. Educar, Curitiba, v. 5, n. 1/2, p. 51-79, jan./dez. 1986.

PARANÁ. Departamento de Arquivo Público (Curitiba, Paraná). Gratificação mensal ao colono Carlos Alberto Templin, servindo como médico na Colonia Assungui, Curitiba. Arquivo Público 408, Curitiba, v. 10, 1873, p. 98.

PARANÁ. Departamento de Arquivo Público (Curitiba, Paraná). Carlos Alberto Tamplin, colono do Assungui, não tem documentos que comprovem pagamento que requer. Arquivo Público 448, Curitiba, v. 20, 1874, p. 157.

PARANÁ. Departamento de Arquivo Público (Curitiba, Paraná). Pedido de Mme. Tamplin de objetos p/a escola da Col. Assungui. Arquivo Público 460, Curitiba, v. 5, 1875, p. 178.

Parish of Old St. Pancra's. s.d. Disponível em: http://www.posp.co.uk/st-pancras-old-church/. Acesso em: 15 jan. 2017.

PICARD, Liza. Education in Victorian Britain. Victorian Britain. s.d. Disponível em: https:// www.bl.uk/victorian-britain/articles/education-in-victorian-britain. Acesso em: 30 out. 2016. 
PROCHASKA, Frank Kimmel. Woman's 'Nature and Mission'. In: Women and Philanthropy in Nineteenth - Century England. Oxford: Clarendon Press; New York: Oxford University Press, 1980. Disponível em: https://books.google.com.br/books?id=Uk-flYAL5lkC\&pg=P $A 4 \& \mathrm{lpg}=P A 4 \& d q=$ sara+delamont+the+contradictions+in+ladies+education\&source=bl\&ots $=8 X 8$ _ciTQH\&sig=Eu2iU-4674ICDVST 1 CV8XYhg 8d4\&hl=ptBR\&sa=X\&ved=OahUKEwiM ILnFx4XQAhWFEpAKHRoPCVOQ6AEIIzAB\#v=onepage\&q=sara\%20delamont\%20the\%20 contradictions\%20in\%2Oladies\%20education\&f=false. Acesso em: 30 out. 2016.

RELATÓRIO sobre a Colônia Assunguy, apresentado a ambas as casas do Parlamento por Ordem de Sua Majestade. Londres-1 875. In: Monumenta. Imigração para o Brasil. Curitiba: Aos Quatro Ventos, 1998.

REMY-HÉBERT, Brigitte. The first women's movements. Suffragist struggles in the 19th and early 20th centuries. s.d. Disponivel em: http://www.ffki.fu-berlin.de/academics/ SummerSchool/Dateien20 11 /Papers/juncker_remy.pdf. Acesso em: 30 out. 2016.

SCOTT, Joan Wallach. Gênero: uma categoria útil de análise histórica. In: Educação e Realidade, Porto Alegre, v. 20, n. 2, p. 71-99, jul./dez. 1995.

TAMPLIN, Caroline. LETTER. Rio Turvo, Colonia Assungui, Paraná, May 14th 1871.

Diary for 1881. Curitiba, 27 nov. 1880.

Diary for 1881. Curitiba, 29 nov. 1880.

TRINDADE, Etelvina Maria de Castro. Clotildes ou Marias: mulheres de Curitiba na Primeira República. Curitiba: Fundação Cultural, 1996.

Profa. Dra. Ana Maria Rufino Gillies Universidade Estadual do Centro-Oeste

Departamento de História

Programa de Pós-Graduação em História Grupo de Pesquisa "Cultura, Etnias, Representações"

Grupo Interdisciplinar de Pesquisa em Arte E-mail | amrgillies@irati.unicentro.br rufinogillies@hotmail.com

Recebido 7 nov. 2016 Aceito 10 jan. 2017 